\title{
Family basics: a scientific administrative reality
}

\begin{abstract}
This article manages the analysis and recognition of the family's administrative and organizational behavior without formal training to achieve their daily basic needs. Theories such as Scientific Administration, Management and Organizational Science, Hierarchy of Basic Needs and the Social System Theory are applied to align the analysis and conclusion. It concludes that Family Organization as part of a socioeconomic micro and macro social group is also using formal and scientific process to reach their goals but without explicit training for that.
\end{abstract}

Keywords: family, needs, administrative, hierarchy, requirements, communication
Volume 5 Issue 5 - 2018

\author{
Sandra Velez Candelario \\ Consultant and Independent Researcher, Family Organizational \\ Science (US Registered Trademark)/Young Human Capital \\ Research, USA
}

Correspondence: Sandra Velez Candelario, Consultant and Independent Researcher, Corp, USA, Tel 786808 8064, 33 I 77 2292, Email velezcandelario@outlook.com

Received: October 28, 2017 | Published: September 07, 2018

\section{Introduction}

The family, as a human organization, was created long, long ago. The bible is the first formal document that explains in black and white the creation of the family organization as a human group to share love, food, privacy, reproduction and material things, for example; Adam, Eva and descendants; John, Mary and Jesus, and so many others groups created to share love and material capital to survive. ${ }^{1}$ Explained that families are a socio-economic organization with blended organizational characteristics where formal and informal processes are at work at the same time and influencing their general socio-economic community and development. Other scientists explained that the family is a group of human beings living together below the same roof, organized in formal roles; father, mother, sons, etc. Those usually have consanguineous links and sometimes do not. They share the same socio-economic existence and affective feelings that agglutinate them. This social group passes by some natural stages; birth, increase, multiplication, decadence and transcendence. ${ }^{2}$

Otherwise, this is also a basic social unit consisting of parents and their children, considered as a group, whether dwelling together or not. It is also a social unit consisting of one or more adults together and the children of one person, one couple collectively, or the spouse and children of one person. ${ }^{3}$ Others scientists, such as, ${ }^{4}$ defined family as an informal group because this social organization escapes from a formal organization's requirements. They explained that informal organizations develop their own social relations inside the formal organizations. This includes social relations, as well as values and norms that can be totally different from a formal organization's such as a business. According to them, these informal organizations are good for the formal organizations because they can fill a part of their needs, such as affectivity.

Family structures in the group consist of the systematic human relations. ${ }^{5}$ This system is interconnected with other systems such as the biological, the psychological, the social, and the ecological ones, passing by the circle of birth, grow, multiply and die. But, how does this human organization survive and satisfy their basic needs? What are their basic needs? How do they organize themselves to become successful both individually and as a group?

\section{Family as an organization and why they become organized}

The family organization, even when they have different compositions, is still a group of human beings that have to be alive and developing skills. They also have to reach their group's goal, vision and mission ${ }^{1}$ expose that this organization has to apply formal administrative tools in its daily life to grow as a socioeconomic organization. Those tools include a leadership model, a hierarchy (power levels), task division, schedules, administrative style, communication process, environmental atmosphere, and organizational culture. They explain that to manage their group and their members effectively and prepare them to be a part of the larger community, they have to be organized.

In the administrative and management process, organizing is aligned with planning. It is a function in which the synchronization and combination of human, physical, and financial resources takes place. All of these three resources are important to get results. Therefore, organizational function helps in achievement of results, which in fact is important for the functioning of a concern. According to, ${ }^{6}$ organizing is a function by which the concern is able to define the role positions, the related jobs, and the co-ordination between authority and responsibility. A manager always has to organize in order to get results. ${ }^{7}$ Expressed that humans have been organizing and cataloging the world for a long, long time. Google's goal is to catalog the whole Internet. In the 18th century, Denis Diderot wanted to collect all of the world's knowledge in his encyclopedia. Philosophers have been creating systems in order to comprehend the whole world. And even before that, agrarian societies have been organizing the land into fields and pastures. But, why is that? Why do we value order over chaos? Why is it so obvious to us that dividing a land into several fields is far better than just randomly growing crops?

The benefits to being organized provide you with safety because disorganized life is very stressful because you never know if there is any danger waiting for you. Security, stability, freedom from fear, those sound like things that being organized can give you. But being organized also gives you self-esteem. Among other things, having self-esteem means that you just know you can deal with whatever life throws at you. When you are organized, you are more in control. You know you can deal with things, since you know what there is to be deal with in the first place. And once you fulfill your self-esteem needs, self-actualization becomes an important need for you as well. This is where your express your creativity and talents. When you don't have safety, it means that one of your most basic indeed is not being met. In other words, when you are disorganized, you just don't feel completely stable, secure and free from fear. It is a similar situation with your self-esteem needs. When disorganized, it is just difficult to feel like a master of your life and attain achievement, respect and 
recognition. When these important needs are not met, your highest needs of self-actualization (creativity, fulfillment, purpose) cannot be fully expressed and met either, since you are preoccupied with your unmet lower needs. ${ }^{7}$

Explains that more than $80 \%$ of people polled in a 2010 survey said that being organized improved their work performance. ${ }^{8}$ Being organized may lead to feeling more in control and having more mental energy. Organized people are conscientious, goal-oriented, optimistic, not always be open to new ideas, decision makers, they capture, calendar and contain, they let go of perfectionism, they are unit ask, they have a do-it-now attitude, they prepare and ask for help. They also know when they do their best work and enjoy destress. Those scientific observations are a very strong reason to justify family scientific organizational process as the way to be successful as a organization.

\section{Family organization basic needs and their administrative reality}

Administration is a science; so many scientists from the $21 \mathrm{st}$ century explain how administration works and how this can help a human being's productivity within their organized groups. From the Scientific School of Management ${ }^{9}$ to the Human Relations Movement and many others, administration is an official scientific process. ${ }^{10}$ Explain that family organizations can't get out of this scientific instrument because it has so many formal and informal things to manage. They explain that families as a human organization have to apply a scientific method to effectively administrate and organize their groups.

Organizing is one of the most important things to do during the scientific administrative process. ${ }^{11}$ Explained in his theory, named Hierarchy of Needs, about organizing human beings basic needs. Maslow exposed that when human beings want to reach their needs, they should organize those by priorities. He created a pyramid to organize human being needs according to his scientific analysis. Maslow stated that people are motivated to achieve certain needs and that some needs take precedence over others. He also explained that physical survival is our most basic need, motivating our behavior to reach anything to achieve what they need to be alive. Once that level is fulfilled, the next level up is what motivates us, and so on Figure 1.

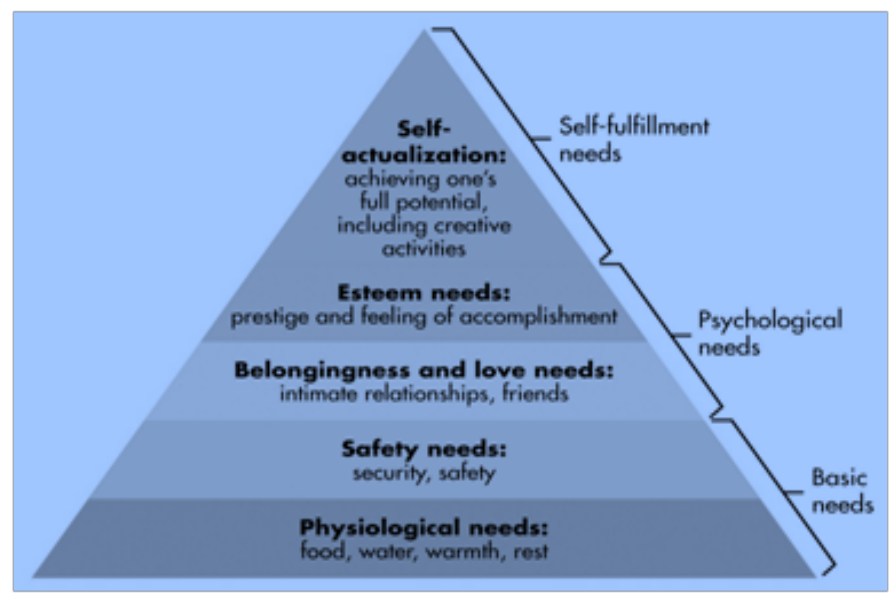

Figure I Physiological needs.
Exposed physiological needs as the most motivational ones. ${ }^{11}$ Those include food, water, warmth, and rest. To achieve that first level of basics needs, as Maslow exposed, humans have to compete with their equals within work organizations to receive money, the modern societies' exchange method. Money is a piece of gold, silver, or other metal in pieces of convenient form stamped by public authority and issued a medium of exchange and measure of value. ${ }^{12}$ Money is an officially coined or stamped metal currency. ${ }^{13}$ Anything of value that serves as a generally accepted medium of financial exchange, legal tender for repayment of debt, standard of value, unit of accounting measure, and means to save or store purchasing power. ${ }^{14}$ Families have to manage their financial issues in accordance with how their macro social financial group does it following the legal money management process. This exchange method has two forms to become rich: by formal business development that includes job positions, or by informal business processes (make money without legal supervision). The formal work organizations have to contract capable human capital to develop products or services to exchange those for money. Those capabilities include social skills to deal with other equals during the competition to acquire money.

To understand how hard can be to family leaders and subordinates manage their behavior to reach their group basic needs without trained is very necessary review one of the most famous theories about the human being's social condition, the Human Ecology Theory. Urie Bronfenbrenner ${ }^{15}$ states that human development is influenced by the different types of environmental systems. This theory helps us understand why we may behave differently when we compare our behavior in the presence of our family and our behavior when we are in school or at work. This theory also holds that we encounter different environments throughout our lifespan that may influence our behavior in varying degrees. These systems include the micro system, the mesosystem, the exosystem, the macro system, and the chronosystem.

The micro system's setting is the direct environment we have in our lives. Your family, friends, classmates, teachers, neighbors and other people who have a direct contact with you are included in your micro system. The micro system is the setting in which we have direct social interactions with these social agents. The theory states that we are not mere recipients of the experiences we have when socializing with these people in the micro system environment, but we are contributing to the construction of such environment. ${ }^{15}$

The mesosystem involves the relationships between the microsystems in one's life. This means that your family experience may be related to your school experience. For example, if a child is neglected by his parents, he may have a low chance of developing positive attitude towards his teachers. Also, this child may feel awkward in the presence of peers and may resort to withdrawal from a group of classmates. ${ }^{15}$ The exosystem is the setting in which there is a link between the context where in the person does not have any active role, and the context where in is actively participating. Suppose a child is more attached to his father than his mother. If the father goes abroad to work for several months, there may be a conflict between the mother and the child's social relationship, or on the other hand, this event may result to a tighter bond between the mother and the child. ${ }^{15}$

According to Bronfrenbrenner, ${ }^{15}$ the macrosystem setting is the actual culture of an individual. The cultural contexts involve the 
socioeconomic status of the person and/or his family, his ethnicity or race and living in a still developing or a third world country. For example, being born to a poor family makes a person work harder every day. Otherwise, the chronosystem includes the transitions and shifts in one's lifespan. This may also involve the socio-historical contexts that may influence a person. One classic example of this is how divorce, as a major life transition, may affect not only the couple's relationship but also their children's behavior. According to a majority of research, children are negatively affected on the first year after the divorce. The next years after it would reveal that the interaction within the family becomes more stable and agreeable. ${ }^{15}$

This theory, published in 1979, has influenced many psychologists in terms of the manner of analyzing the person and the effects of different environmental systems that they encounter. The ecological systems theory has since become an important theory that became a foundation of other theorists' work. During the process of basic needs achievement by family organizations, any social human creature of this group has to act according with the social interaction realities by each one of these Ecology System Theory areas. ${ }^{15}$ These social human being characteristics show how difficult and danger can be reach Maslow's basic needs for the organized human being without formal scientific administrative Knowledge in today's society when this group use those tools without become train for it.

Otherwise, within this first level, Maslow also included security and safety needs, such as a house or a place to rest and reproduces the race. To reach this goal, people use money or credit. Credit is a modern economy tool for exchange. Credit mean credibility, commendation of honor given for some action, quality, etc. ${ }^{12}$ This also is an agreement based largely on trust under which goods, services, or money are exchanged against a promise to pay later. ${ }^{16}$ Human beings use credit as a daily tool to reach what they need to become warm; a house, close, shoes, gas, etc. Credit as an administrative tool is regulated by government statutes to control failures to the agencies that give that credit options to their clients. This modality makes both parts responsible to manage the exchange process of these goods, credit line representative and the client with "credibility". Laws and formal process have to be managed by both parts of the exchange process when using the credit method. Any family member that uses credit lines to buy a house or any other goods to be warm has to manage this credit applying scientific processes such as mathematics, law statements, regulators entities, etc

Maslow developed a second level of basic needs named psychological ones (belongingness and love needs). To acquire these basic needs, family members usually use their family leader role models to share love and emotional expressions. Otherwise, to receive and share love, modern societies will apply spontaneous social activities to select equals with this purpose. They also use social media group associations and sometimes pay to become part of those. Prestige and feelings of accomplishment will become created during the social interactions in human lives. During these social interactions within the family stage, human beings share knowledge, values, and abilities with their equals. Depending on their ability to communicate, they influence others, affecting their self esteem and prestige inside this organization. Today's social control laws create legal processes to apply in the informal setting named family during their social affective interaction. Antique societies permitted sexual activities between some family members with first line blood connection, but today's scientific influence pushed the creation of legal control in sexual interaction between family first line blood such as brothers with sisters, fathers with daughters, mothers with sons, etc. The biology, physiology, psychology, and other sciences advantage proof that sexual relations between family members from first biosocial connections are a high risk of physical defects, psychological disorders, and many others issues.

Otherwise, the legal social control also managed the way that family leaders will teach their subordinates (children). The legal system in modern societies control physical contact between family leaders and subordinates during their training process. They also supervise psychological treatment, specifically between high power positions to low power ones. During the affective interaction process, family members have to be clear about how they can share affectivity and how this should not be expressed within their organization. To properly manage a family's affective activities, its managers have the responsibility to understand how legal systems work in this matter.

To conclude, ${ }^{11}$ ended his pyramid with the last basic need, selffulfillment. This basic need includes self-actualization that includes creative activities. Today's family leaders accomplish this need by sending their members to school or colleges. School is a formal organization that organizes their teamwork to become effective and successful using learning theories and scientific management processes. Those works by helping the human being update their knowledge in accordance with the macro-social group's socioeconomic needs. As a formal organization, the way they work to reach their goals is regulated by law. Families also use colleges and universities, both work in the same way that school does but usually do not include minors as part of their impact population. College works to help people develop specialized knowledge, achieving one's full potential including creative activities.

Is very clear that in family organizations, adult and minor members cannot work independently using pure improvisation to manage their actions and activities during their reaching basic need process. The organized human beings living in the same space named family manage everyday formal activities that require formal and scientific knowledge to participate and become successful. Normally they use formal processes without explicit training to manage family group such as; a) write letters to excuse their kids when they are not going to assist school, b)accountability when they have to sale or buy, c) communication process with governmental organizations to ask for assistance, d)deal and negotiate with different professional human resources that will help them to achieve part of their needs, e)develop young human capital works and social skills of different stages and abilities within their family organization, f) manage adult human capital such as neighbor's leadership, and many others. Family's organization leaders and subordinates are using formal administrative and organizational behavior to reach their goals as a family organization every single day. They manage their daily live without a formal training to do it adequately and without counterproductive physical, economic or psychological consequences. ${ }^{17}$

\section{Acknowledgements}

None.

\section{Conflict of interest}

Author declares there is no conflict of interest. 


\section{References}

1. Velez S, Rosario I, Mendez V. Desarrollo del Capital Humano desde la Organización Familiar con la Intervención de la Psicología Industrial Organizacional en un Grupo de Familias del Sur y Norte de Puerto Rico. Biblioteca Encarnación Valdés, PUCPR, Ponce, PR. 2009.

2. Interamerican Institute of Children. Family Concept. 2017.

3. Dictionary. Family Definition. 2017.

4. Guillen, Guill . Psicología del Trabajo Para Las Relaciones Laborales. 1ra edic. McGraw Hill/Interamericana de España. 2000.

5. Dionini OA. Sexualidad y Familia Crisis y Desafios Frente al Siglo XXI Ira ed. Buenos Aires: C Educative Publication Center. 2004.

6. GL perry. Human Relations Management Theory Basics. 2017.

7. Novotny J. Is being organized a basic human need? 2014.

8. Klein S. 14 Habits From Organized People That We ALL Should Borrow. 2015.
9. Taylor FW. The principles of scientific management. 1911.

10. Velez S, Rosario I, MéndezV, et al. Family, Human Capital and Industrial/ Organizational Psychology. Interamerican Journal of Psychology. 2016;50(3):433-440.

11. McLeod S. Maslow's Hierarchy of Needs. 2007.

12. Webster's Encyclopedic Unabridged Dictionary of the English Language. Money Definition. Gramercy Books, New York/Avenel. 1996.

13. Merriam Webster. Definition of money. 2017.

14. Business Dictionary. Definition of Money. 2017.

15. Sincero SM. Ecological Systems Theory. 2017.

16. Business Dictionary. Definition of Money. 2017.

17. New York, London, Harper \& Brothers. 